\title{
REFLEXÕES SOBRE AS RECORRENTES JUSTIFICATIVAS DE AMPLIAÇÃO DA JORNADA ESCOLAR NA EDUCAÇÃO BRASILEIRA'
}

\author{
Alessandra Victor do N. Rosa² \\ Valdeney Lima da Costa ${ }^{3}$ \\ Flávia Russo Silva Paiva ${ }^{4}$
}

\section{RESUMO}

O presente artigo analisa as configurações da ampliação da jornada escolar que foram e estão sendo planejadas para as escolas públicas no âmbito do Ensino Fundamental, relacionando a problemática consubstanciada entre essa ampliação e suas distintas finalidades. Para tanto, levantamos as seguintes questões: Como vem se efetivando a ampliação da jornada escolar no contexto da educação pública brasileira? Quais as justificativas mais recorrentes para essa ampliação? Visando ao desenvolvimento deste trabalho realizamos uma pesquisa bibliográfica a partir dos estudos de Parente (2006, 2010), Teixeira (1977), Ribeiro (1986), Arroyo (1986), Cavaliere (2002, 2007, 2009), Arcoverde (2003), Algebaile (2009), Maurício (2009), Monlevade (2009) e Rosa (2016). Os resultados deste estudo evidenciam que a ampliação da jornada escolar no contexto da educação pública brasileira, e voltando-se ao ensino fundamental, tem se realizado, basicamente, a partir da extensão do tempo de permanência dos estudantes na escola e a partir de diferentes

1 Ensaio apresentado em 2010 no Seminário Regional da ANPAE, realizado em Recife/PE. Revisto e ampliado, visando o foco desta publicação.

2 Técnica em Assuntos Educacionais da Universidade Federal do Estado do Rio de Janeiro (UNIRIO). Doutora em Educação pela Pontifícia Universidade Católica do Rio de Janeiro (PUC-Rio). Pesquisadora do Núcleo de Estudos Tempos, Espaços e Educação Integral (NEEPHI)/UNIRIO. E-mail: victor.alessandrarosa@gmail.com.

3 Professor Assistente da Universidade Estadual do Piauí (UESPI). Doutorando em Educação pelo Programa de Pós-Graduação em Educação (PPGEdu), da Universidade Federal do Estado do Rio de Janeiro (UNIRIO). Pesquisador do Núcleo de Estudos Tempos, Espaços e Educação Integral (NEEPHI)/UNIRIO. E-mail: pedagogo.ney@gmail.com.

4 Doutoranda em Educação pelo Programa de Pós-Graduação em Educação (PPGEdu) da Universidade Federal do Estado do Rio de Janeiro (UNIRIO). Pesquisadora do Núcleo de Estudos Tempos, Espaços e Educação Integral (NEEPHI)/UNIRIO. E-mail: flavia.paiva@ufv.br. 
entendimentos de como tal tempo escolar estendido deve ser ocupado, bem como sob distintos fundamentos para sua ampliação. Diante disso, observamos que as questões que envolvem a ampliação da jornada escolar, atualmente, se configuram a partir de múltiplas concepções, ideias e práticas emergentes na educação brasileira que precisam ser exploradas, sobretudo de modo aprofundado em trabalhos acadêmicos.

Palavras-chave: Políticas educacionais. Escola pública. Jornada escolar ampliada.

\section{REFLECTIONS ON RECURRING JUSTIFICATIONS EXPANSION OF SCHOOL DAY IN BRAZILIAN EDUCATION}

\section{ABSTRACT}

This article analyzes the settings of the extension of the school day that were and are being planned for public schools in the elementary school, relating the problem embodied between this expansion and its different purposes. Therefore, we raise the following questions: How has been effective the expansion of the school day in the context of Brazilian public education? What are the most frequent reasons for this expansion? Aiming at the development of this study conducted a literature search from studies of Parente (2006, 2010), Teixeira (1977), Ribeiro (1986), Arroyo (1986), Cavaliere (2002, 2007 and 2009), Arcoverde (2003) Algebaile (2009), Maurício (2009), Monlevade (2009) and Rosa (2016). The results of this study show that the expansion of the school day in the context of Brazilian public education, and returning to the elementary school, has done basically from the extension of students' time spent at school and from different understandings how this extended school time should be occupied and under different foundations for its expansion. Thus, we observe that the issues surrounding the expansion of the school day, currently, are configured from multiple views, ideas and practices emerging in Brazilian education that need to be explored, especially in depth in academic papers.

Keywords: Educational policies. Public school. Extended school day. 


\section{$\begin{array}{llll}\text { REFLEXIONES SOBRE } & \text { LAS } & \text { RECURRENTES }\end{array}$ JUSTIFICACIONES DE AMPLIACIÓN DE LA JORNADA ESCOLAR EN LA EDUCACIÓN BRASILEÑA 5}

\section{RESUMEN}

El presente artículo analiza las configuraciones de la ampliación de jornada escolar que han sido y están siendo planeadas para las escuelas públicas en el ámbito de la Enseñanza Fundamental, relacionando la problemática consustanciada entre esa ampliación y sus diferentes finalidades. Para eso, planteamos las siguientes cuestiones: Como se efectiva la ampliación de la jornada escolar en el contexto de la educación pública brasileña? Cuáles son las justificaciones más frecuentes de esta ampliación? Buscando el desarrollo de este estudio se há llevado a cabo una búsqueda bibliográfica a partir de los estudios de Parente $(2006,2010)$, Teixeira (1977), Ribeiro (1986), Arroyo (1986), Cavaliere (2002, 2007 у 2009), Arcoverde (2003), Algebaile (2009), Maurício (2009), Monlevade (2009) y Rosa (2016). Los resultados de este estudio muestran que la ampliación de la jornada escolar en el contexto de la educación pública brasileña, y se volviendo a laenseñanza primaria, se há llevado a cabo, básicamente, a partir de la ampliación del tiempo de permanência de los estudiantes en la escuela y de diferentes entendimientos de como este tiempo escolar ampliado debe estar ocupado, bien como bajo diferentes bases para su ampliación. Ante esto, hemos observado que las cuestiones relacionadas con la ampliación de la jornada escolar, en la actualidad, se configuran desde múltiplas concepciones, ideas y prácticas emergentes en la educación brasileña que necesitan ser exploradas, sobretodo en profundidad en trabajos académicos.

Palabras clave: Políticas educativas. Escuelas públicas. Jornada escolar extendida.

5 Trabajo presentado en el Seminario Regional de ANPAE 2010, celebrada en Recife / PE. Revisada y ampliada, con el objetivo el objetivo de esta publicación. 


\section{Introdução}

Do conjunto das refl exões que envolvem a educação brasileira, a ampliação da jornada escolar ainda é uma temática pouco explorada em pesquisas acadêmicas (ROSA, 2016). Nos últimos anos, observamos um aumento de experiências em escolas da rede pública de ensino com esta perspectiva, como uma estratégia que visa alcançar, dentre outras fi nalidades, uma educação integral ${ }^{6}$ e/ou a melhoria da qualidade da educação brasileira (ROSA, 2016).

Diante disso, objetivamos, neste artigo, analisar as confi gurações do aumento da jornada escolar que foram e estão sendo planejadas para as escolas públicas no âmbito do Ensino Fundamental, relacionando a problemática consubstanciada entre essa ampliação e suas distintas fi nalidades. Para tanto, levantamos as seguintes questões: Como vem se efetivando a ampliação da jornada escolar no contexto da educação pública brasileira? Quais as justifi cativas mais recorrentes para essa ampliação?

Visando responder aos questionamentos apresentados, realizamos uma pesquisa bibliográfi ca a partir dos estudos de Parente (2006, 2010), Teixeira (1977), Ribeiro (1986), Arroyo (1986), Cavaliere (2002, 2007, 2009), Arcoverde (2003), Algebaile (2009), Maurício (2009) Monlevade (2009) e Rosa (2016).

Em termos estruturais, organizamos este artigo em três momentos. No primeiro, destacamos alguns entendimentos sobre o tempo escolar. No segundo, apresentamos brevemente uma discussão acerca da ampliação da jornada escolar. No terceiro, ressaltamos algumas justifi cativas que reforçam tal ampliação. E, por último, tecemos uma

6 Compreendemos educação integral como uma formação escolar voltada para o desenvolvimento dos aspectos cognitivos, culturais, éticos, estéticos e políticos, dentre outros. 
discussão acerca da relação entre a ampliação da jornada escolar e as distintas finalidades com as quais esta vem se efetivando.

A fim de iniciarmos nossa reflexão, questionamos: De que tempo escolar nos referimos quando pensamos a jornada ampliada na escola?

\section{Os tempos que se entrecruzam na educação escolar}

Ao abordarmos o tempo no âmbito da educação escolar consideramos importante, primeiramente, compreendêlo em suas diferentes noções, conforme indica Parente (2006, 2010): tempos de escola, tempos de escolarização e tempos na escola.

A primeira noção do tempo denominada tempos de escola, refere-se ao início e ao tempo de duração da escolarização, ou seja, está associada à definição de uma idade específica para o sujeito se matricular na escola e de um período em que este deve permanecer nesta instituição. No Brasil, por exemplo, a Lei no 11.274/2006 estabelece que o ensino fundamental obrigatório tenha duração de nove anos e a Emenda Constitucional no 59/2009, altera o inciso I do art. 208 da Constituição Federal de 1988 regulamentado que a idade mínima para efetuar matrícula em escolas regulares passa a ser aos quatro anos de idade, mas legislações anteriores determinavam idades e períodos diferentes.

Quanto à dimensão do tempo escolar intitulada tempos de escolarização, Parente (2010) a compreende como as formas de organizar a educação escolar, seja em séries, ciclos, dentre outras. No âmbito da educação escolar brasileira, a forma predominante consiste no modelo seriado, organizando o tempo de escolarização em séries anuais, embora a Lei no. 9. 394/96 sinalize a flexibilidade dessa organização.

Art.23. A educação básica poderá organizar-se em séries anuais, períodos semestrais, ciclos, alternância 
regular de períodos de estudos, grupos não-seriados, com base na idade, na competência e em outros critérios, ou por forma diversa de organização, sempre que o interesse do processo de aprendizagem assim o recomendar. (BRASIL, 1996).

Por fim, tempos na escola é uma noção de tempo escolar que se refere às construções consolidadas no interior das instituições escolares - os novos tempos que são criados pela própria escola, compreendendo, principalmente, "as formas de organização do trabalho pedagógico na escola e as iniciativas de educação em tempo integral." (PARENTE, 2006, p. 23).

Conforme mencionado anteriormente, é nessa dimensão do tempo escolar que se insere a duração da jornada diária escolar que, na legislação brasileira, é abordada no Art. 34 da Lei de Diretrizes e Bases da Educação Nacional (LDBEN), determinando que a jornada escolar no ensino fundamental deva incluir pelo menos quatro horas de trabalho efetivo em sala de aula, sendo paulatinamente ampliado o tempo de permanência na escola e que $\nabla^{\prime}$ “...] o ensino fundamental será ministrado progressivamente em tempo integral, a critério dos sistemas de ensino" (BRASIL, 1996).

Embora a LDBEN/1996 tenha mencionado a expressão tempo integral, tal aparato legal não a definiu. A definição somente foi apresentada pelo Decreto №. 6.253/2007, que além de regulamentar o Fundo de Desenvolvimento da Educação Básica de Valorização dos Profissionais da Educação (FUNDEB), estabeleceu:

Art. 4․ Considera-se educação básica em tempo integral a jornada escolar com duração igual ou superior a sete horas diárias, durante todo o período letivo, compreendendo o tempo total que um mesmo aluno permanece na escola ou em atividades escolares. (BRASIL, 2007).

A partir dessa definição, em termos legais, de tempo integral, cabe-nos mencionar que em relação à jornada ampliada, esta 
se refere a um período maior que quatro horas e que, por isso, inclui a definição de tempo integral (MENEZES, 2009).

Expostas essas abordagens do tempo escolar, nos deteremos, no próximo item, a problematizar um aspecto da dimensão tempos na escola - a ampliação da jornada escolar.

\section{Sobre a ampliação da jornada escolar no contexto da educação pública brasileira}

A organização da jornada escolar, na perspectiva de sua ampliação, vem se constituindo como objeto dos debates acerca da qualidade da educação. No âmbito dessas discussões, sobressaem opiniões sobre a suficiência ou não da quantidade de dias/horas destinadas às atividades escolares. Em verdade, essa polaridade conceitual se apresenta como recorrente na história da educação brasileira.

Na década de 1950, por exemplo, Anísio Teixeira já refletia sobre o curto período diário da escola primária no Brasil. Analisando o contexto educacional da época, e mais precisamente, o papel social da instituição escolar, o intelectual brasileiro defendia que seu funcionamento não poderia ocorrer em tempo parcial. Nas palavras dele

[...] sendo a escola primária a escola por excelência formadora, sobretudo porque não estamos em condições de oferecer a toda a população mais do que ela, está claro que, entre todas as escolas, a primária, pelo menos, não pode ser de tempo parcial. [...] A escola primária visando, acima de tudo à formação de hábitos de trabalho, de convivência social, de reflexão intelectual, de gosto e de consciência, não pode limitar as suas atividades a menos que o dia completo. Deve e precisa ser de tempo integral para os alunos e servida por professores de tempo integral.

(TEIXEIRA, 1977, p.79). 
Como podemos observar, Anísio Teixeira foi um dos grandes defensores da ampliação do tempo diário de atividades escolares, bem como do direito à educação pública e laica no país. Nesse ínterim, ele compreendia que parte integrante desse direito deveria ser uma jornada completa para as crianças na instituição escolar, a fim de combater a organização e funcionamento desta em três ou mais turnos e a fragmentação do processo de ensino-aprendizagem.

Contudo, embora experiências de escolas de jornada completa tenham sido projetadas e implementadas por Anísio Teixeira, nos anos 1930, no Rio de Janeiro e, posteriormente, nos anos 1950, em Salvador (BA), pouco se debateu sobre a ampliação da jornada escolar naqueles tempos. Esse educador baiano elaborou um plano educacional que compreendia a criação de prédios conjugados, divididos em escolasclasse e escolas-parque, de modo a atender os alunos em dois turnos e, consequentemente, garantir sua presença na escola por período ampliado. Sob a inspiração dessa proposta de escolas que, ao ocupar o cargo de Secretário de Educação do Estado da Bahia, Anísio projetou o Centro Educacional Carneiro Ribeiro (CECR), o qual foi inaugurado no ano de 1950, num bairro periférico da cidade de Salvador, Bahia, consistindo em um complexo composto por quatro escolas-classe e uma escola-parque. O CECR destinava-se a atender 4.000 alunos, sendo que cada escola-classe atenderia 1.000, em dois turnos de 500. Desse modo, a escola-parque receberia os 4.000 alunos dividindo-os em dois turnos, ou seja, atenderia 2.000 alunos no turno matutino e 2.000 alunos no turno vespertino. Assim, os estudantes frequentavam a escola-classe em um turno e, no turno oposto eram recebidos pela escola-parque onde também se alimentavam e tomavam banho (TEIXEIRA, 1977).

Mais tarde, o debate sobre a jornada ampliada se intensificou nos anos 1980 e esteve circunscrito principalmente no Estado do Rio de Janeiro (CAVALIERE, 2002). As discussões foram decorrentes da implementação dos Centros Integrados de Educação Pública (CIEPs) nesse estado, pelo governador Leonel Brizola e seu vice, Darcy Ribeiro, que tinha sido parceiro de Anísio Teixeira nos projetos de criação das Escolas Classe/Escola Parque do Distrito Federal. 
Darcy Ribeiro (1986) afirmava que o aspecto crucial do baixo rendimento escolar residia na exiguidade do tempo de atendimento dado as crianças. Segundo ele, as crianças pobres, diferente das crianças das classes mais favorecidas que tem em casa quem estude com elas algumas horas extras, só dispunham da escola para lhes ensinar. Dizia também que "[...] em todo o mundo se considera que cinco horas de atenção direta e contínua ao aluno por seu professor é a jornada mínima indispensável." (RIBEIRO, 1986, p.33). Partindo desse pressuposto, o educador implantou o dia completo nos CIEPs, no Rio de Janeiro, decretando assim, o fim do terceiro turno diário nas escolas deste estado do país.

Passados alguns anos, a discussão sobre a jornada escolar ainda continua sendo polêmica no contexto da educação brasileira. Por um lado, existem educadores que defendem a ampliação da jornada escolar como uma estratégia para possibilitar o desenvolvimento de um número maior de atividades e conteúdos escolares. Por outro, existem aqueles que compreendem a instituição escolar como um espaço de proteção dos sujeitos em vulnerabilidade, justificando, portanto, o aumento do tempo do aluno, como uma demanda social.

Tais fatos podem ser identificados a partir da discussão em torno das diferentes concepções de jornada ampliada no contexto atual. Cavaliere (2007), por exemplo, destaca que existem quatro concepções de escola de tempo integral que estão em disputa no cenário brasileiro, denominadas por ela como: (1) assistencialista; (2) autoritária; (3) democrática; (4) multissetorial.

Deacordo com Cavaliere (2007), a concepção assistencialista é aquela que propõe que a escola seja um espaço de cuidado dos educandos, ou seja, que ofereça banho, alimentação, atendimento médico e odontológico, entre outros. Já a autoritária visa proteger os alunos, mantendo-os longe das ruas e, portanto, dos perigos sociais.

A concepção democrática e a multissetorial partem de pressupostos diferentes da perspectiva assistencialista e autoritária. 
Na democrática o que vigora é a valorização da formação escolar do educando e a oferta de conhecimentos sócio-historicamente construídos. Já a multissetorial seria aquela que não possui vínculo direto com a escola, ou seja, o aluno tem sua jornada ampliada, mas outras instituições são responsáveis pelo desenvolvimento de atividades nesse período estendido.

Dando pouca ênfase a essas questões, os que comungam com a necessidade de ampliação da jornada escolar reivindicam maior tempo também para o trabalho docente, de modo que este se desenvolva numa mesma escola. Esse aspecto evitaria a sobrecarga de muitos professores que trabalham em escolas diferentes, em turnos distintos, além de concorrer para o envolvimento destes com a própria instituição escolar. Ainda sobre essa questão, Monlevade (2009, p. 13) expõe:

[...] a Internacional da Educação, confederação sindical que congrega as associações profissionais de todo o mundo, defende não somente a jornada integral e exclusiva como a composição de trabalho dividida entre horas de docência e horas de atividades de formação continuada, estudos pessoais, preparação dos cursos, avaliação dos alunos, integração nos coletivos escolares e contatos com a comunidade local. Sem o correspondente ordenamento da jornada docente, ficam como que anulados os bons resultados que poderia trazer para a qualidade da aprendizagem o regime de jornada integral para os estudantes.

Além dos profissionais da educação, as famílias também reivindicam uma jornada escolar ampliada, ou, de forma oposta, criticam a extensão da jornada diária da escola. Em relação aos estudantes, alguns gostam de passar o dia inteiro na instituição escolar, por ser este, em algumas realidades, o único espaço de lazer da comunidade ou ainda por oferecer atividades atrativas, enquanto outros preferem se afastar dela no horário em que não estão em aula. Enfim, a duração do tempo diário escolar divide opiniões dos sujeitos envolvidos com os processos escolares (ROSA, 2016). 
Há que se admitir também que as discussões sobre o tempo diário escolar, por vezes, ultrapassam o campo da escola e também o da educação. Isso quer dizer que, atualmente, essa questão vem sendo analisada também por profissionais de outras áreas, tais como a economia, a estatística, a sociologia, dentre outras. As opiniões parecem também divergentes, porém, ganham destaque o curto tempo de permanência dos estudantes na escola e a carga horária mínima destinada a algumas disciplinas, conforme apontam as pesquisas.

Um estudo organizado pela Fundação Getúlio Vargas, revelou que o tempo de permanência na escola brasileira é bem inferior ao previsto na legislação educacional, que estabelece que a jornada escolar seja de, pelo menos, quatro horas diárias de efetivo trabalho escolar (BRASIL, 1996). De acordo com a referida pesquisa, quando se analisou a jornada diária dos estudantes na faixa etária de 4 a 17 anos, foi observado que cada indivíduo permanecia em média 3,47 horas na escola, ou 208 minutos, enquanto na faixa etária de 15 a 17 anos, a média foi reduzida para 3, 21 (NERY, 2009).

A pesquisa supracitada divulgou ainda que o tempo diário de permanência na escola apresenta médias diferenciadas nos sistemas subnacionais de ensino, com destaque para o Distrito Federal $(4,8)$, São Paulo $(4,25)$ e Rio de Janeiro $(4,14)$, onde as jornadas escolares são mais extensas em relação aos estados do Amazonas $(3,41)$ e do Acre e Rondônia (ambos com 3,35), que apresentaram uma pequena jornada diária escolar. Se comparadas as regiões brasileiras, o Sudeste se sobressai como aquela em que se passa mais tempo diário na escola, em oposição à média da Região Norte.

Embora os resultados do estudo supracitado tenham apontado o curto tempo diário em que as crianças passam nas escolas brasileiras, outra pesquisa ${ }^{7}$ realizada por quatro universidades públicas

7 A pesquisa denominada Educação integral / educação integrada e(m) tempo integral: concepções e práticas na educação brasileira foi encomendada pela extinta Secretaria de Secretaria de Educação Continuada, Alfabetização, Diversidade (SECAD), vinculada ao Ministério da Educação, e desenvolvida pelas Universidades Federal do Estado do Rio de Janeiro (UNIRIO), Universidade Federal de Minas Gerais (UFMG),Universidade Federal do Paraná (UFPR) e Universidade de Brasília (UnB), de 2008 a 2010. 
revelou a existência de múltiplos projetos e experiências de extensão da jornada escolar, em particular, na rede/sistemas de ensino municipais. No geral, a maioria desses projetos se concentram nos estados das regiões sudeste e sul, com destaque para Minas Gerais, São Paulo e Rio Grande do Sul.

No que se refere às características das experiências em processo no país, pode ser observada a existência de diversos formatos organizacionais, no qual a jornada ampliada é sistematizada e vivenciada de distintas maneiras.

Considerando os debates a favor da ampliação da jornada diária escolar, a seguir apresentamos algumas justificativas recorrentes utilizadas para a implementação de projetos e/ou programas com tal fim em nosso país.

\section{Algumas justificativas para a ampliação da jornada escolar}

No bojo das discussões sobre a jornada ampliada dos alunos na ou sob a responsabilidade da escola, sobressaem argumentos que reforçam a necessidade dessa ampliação, muitos deles pautados em naturezas, concepções ou finalidades diversas. Assim, é relevante analisar aspectos como à viabilidade econômica e administrativa quanto à forma de utilização pedagógica dessas horas adicionais (CAVALIERE, 2009).

A proposta de extensão da jornada escolar traz consigo não apenas uma possível finalidade pedagógica, mas, muitas vezes, uma pretensão social e política. Disso decorre que, dependendo do projeto governamental que se tem, a dimensão política ou a preocupação social, podem se sobrepor ao caráter pedagógico desse projeto educacional.

Diante das diversas finalidades que cumpre a jornada escolar ampliada, Cavaliere (2007, p. 1016) ressalta que essa ampliação pode ser respondida ou compreendida de diferentes maneiras, ou seja, 
a) ampliação do tempo como forma de se alcançar melhores resultados da ação escolar sobre os indivíduos, devido à maior exposição desses as práticas e rotinas escolares; b) ampliação do tempo como adequação da escola às novas condições da vida urbana, das famílias e particularmente da mulher; c) ampliação do tempo como parte integrante da mudança na própria concepção de educação escolar, isto é, no papel da escola na vida e na formação dos indivíduos.

Dialogando com o primeiro entendimento exposto pela autora, é possível entender que a utilização dessa justificativa reforça que o aumento da jornada escolar melhora a aprendizagem dos educandos, tendo em vista uma maior permanência destes na escola. Apesar da recorrência desse argumento, não é possível estabelecer uma associação automática entre mais tempo na escola e uma efetiva aprendizagem do aluno.

Ainda sobre essa questão, Arcoverde (2003, p. 383-384) compreende que

A ampliação do tempo, a extensão da jornada escolar ou a maior quantidade de horas de permanência do aluno na escola não é condutor direto para a melhoria da qualidade [...]. Não é a intensidade do tempo de ensino que garante a aprendizagem, mas a efetiva qualidade do trabalho pedagógico.

A segunda compreensão sobre o aumento da jornada escolar se correlaciona com as mudanças operadas na vida urbana, na rotina familiar e nas forças produtivas da sociedade atual. $O$ funcionamento da escola com jornada ampliada, em especial a de tempo integral, atende às necessidades de alguns pais trabalhadores que buscam na escola um local seguro para deixarem seus filhos.

Se a proposta da escola de tempo integral é vantajosa para alguns pais que precisam deixar seus filhos neste espaço enquanto trabalham, por outro lado, pode não ser agradável para outros que 
necessitam da ajuda dos filhos para complementar a renda familiar.

Sabe-se que em alguns lugares do Brasil, crianças deixam de frequentar o ambiente escolar partindo para as ruas. Não é difícil encontrá-las perambulando pelas grandes, e mesmo pequenas, cidades brasileiras, buscando vender balas, doces, bem como outros produtos. No campo, é muito comum pais utilizarem seus filhos como mão de obra para a realização de tarefas domésticas e em outras atividades laborais fora do lar. Nesse sentido, o aumento do tempo de permanência dessas crianças na escola poderia modificar a rotina de trabalho de algumas famílias.

Ainda sobre a segunda justificativa, que argumenta o aumento da jornada escolar como forma de adequação à nova dinâmica familiar, cabe considerar que esta se assenta na constatação de alterações dos papéis sociais. Uma das mudanças perceptíveis na conjuntura familiar diz respeito ao ingresso das mulheres no mercado de trabalho. Diante desse aspecto e também considerando a ocupação dos demais membros familiares, o aumento do tempo diário escolar vem atender a essas exigências da classe trabalhadora que não dispõem de um local seguro e confortável para "guardar os filhos" enquanto se dedicam ao trabalho.

Em relação a terceira justificativa para a jornada ampliada - c) ampliação do tempo como parte integrante da mudança na própria concepção de educação escolar, isto é, no papel da escola na vida e na formação dos indivíduos -a extensão do tempo diário escolar é fruto da própria redefinição do papel assumido pela instituição educativa, convocada a assumir outras funções, para além da instrução. Assim, "[...] a novidade da ampliação do tempo diário estaria na transformação do tipo de vivência escolar, na mudança, portanto, no papel desempenhado pela escola." (ARCOVERDE, 2003, p.1021).

De fato, percebe-se que a escola contemporânea vem assumindo compromissos e responsabilidades que, tradicionalmente, não eram de sua competência (ALGEBAILE, 2009). Contribui para 
isso a ressignificação conceitual que lhe é posta. Nesse sentido, sua compreensão enquanto instituição social exige o reconhecimento da composição em sua gênese de elementos não diretamente voltados para a finalidade de educar e mesmo para o processo educativo em sentido específico (ALGEBAILE, 2009).

Em outro estudo, Cavaliere (2009) retoma mais uma vez a discussão sobre as justificativas para a ampliação do tempo escolar. Segundo a autora, os argumentos para tal pretensão se fundamentam em concepções agrupadas em autoritárias ou assistencialistas, democráticas ou que se pretendem emancipatórias, conforme mencionado no item 2 deste estudo.

Cabe reforçar que a visão assistencialista ou autoritária da jornada ampliada percebe a escola como um espaço destinado ao atendimento das carências sociais, alimentares, culturais e pedagógicas das classes populares. Nessa perspectiva, o mais importante não é a formação escolar, mas os cuidados básicos relacionados à saúde, integridade física, desenvolvimento humano, que proporcionem um bem estar à criança e ao adolescente.

Arroyo (1986, p. 4) ao analisar criticamente as instituições com esse perfil, afirmou que estas

[...] pretendem proporcionar ao educando uma experiência educativa total, que não se limite a ilustrar a mente, mas, que organize seu tempo, seu espaço, que discipline seu corpo, que transforme e conforme sua personalidade por inteiro. O papel do mestre não termina com a lição na sala de aula, essa é apenas uma das tarefas, nem sempre a mais relevante. Do mestre se espera que seja preceptor, educador, e da instituição que seja formadora, não mera instrutora ou informadora.

Esta visão pode ser observada ainda na compreensão de alguns profissionais e autoridades, que atribuem à escola a função de proteção de crianças e adolescentes em situação de risco social. Assim, o 
espaço escolar é pensado como uma instituição preventiva e protetora sendo fundamental a ocupação dos alunos em jornada ampliada.

Para os que partilham desse entendimento, a ampliação da jornada escolar é uma oportunidade para tirar as crianças da rua, protegendo-as dos riscos e mazelas sociais, do trabalho infantil, à medida que são ocupadas com atividades sob a responsabilidade da escola.

O curioso que vem ocorrendo na educação brasileira, é que alguns projetos de ampliação da jornada escolar dos alunos, com vistas à proteção social, fazem uma seleção do público a ser atendido, colocando como uma das prioridades os sujeitos que se encontram em vulnerabilidade social, seja pelo risco do trabalho infantil, exploração sexual, uso de drogas ou induzidos para a criminalidade.

Quanto a isso, compartilhamos do entendimento de Cavaliere $(2012)^{8}$ quando esta pesquisadora considera não ser possível ignorar a situação de vulnerabilidade de muitas crianças e adolescentes em nosso país, no entanto, entende também não ser possível atribuir somente para a escola a função de solucionar tal problemática social. Diante desse contexto, a referida estudiosa defende que a ampliação do tempo escolar propicie o desenvolvimento dos educandos em uma perspectiva mais completa, enfatizando os âmbitos cognitivo, cultural, ético, estético, político, dentre outros, e, desse modo, o estar na escola por mais tempo fará com que, por consequência, as crianças e adolescentes fiquem protegidos das diversas situações de vulnerabilidade as quais são expostas.

Ainda sobre a visão autoritária de jornada ampliada, ao nosso ver, duas advertências precisam ser ratificadas: (1) é preciso reconhecer que a escola não está isenta da problemática social, pois nela também se manifestam a violência física e moral da sociedade atual; (2) é necessário enfatizar que não é papel da escola tirar as crianças da rua, caso contrário corremos o risco de transformar a instituição numa espécie de reformatório ou orfanato. Nesse sentido, Maurício (2009, p.

8 Palestra proferida pela Prof. a Dr. a Ana Maria Villela Cavaliere no II Seminário Nacional de Educação Integral, Rio de Janeiro, 2012. 
56) também já reforçou que "A criança deixar de estar na rua pode ser uma consequência da escola de horário integral" e não seu objetivo primeiro.

No que tange à concepção democrática, a mesma considera a jornada escolar ampliada como um caminho na busca por uma educação concreta, sólida, no que tange ao repasse dos conteúdos historicamente acumulados, na formação cultural e política dos indivíduos, por meio de uma experiência democrática e coletiva. "A permanência por mais tempo na escola garantiria melhor desempenho em relação aos saberes escolares, os quais seriam a ferramenta para a emancipação" (CAVALIERE, 2007, p.1029).

Por fim, além dessas concepções de jornada ampliada, existe aquela que independe da organização da instituição escolar, compreendida por Cavaliere (2007) como de natureza multissetorial. Nesta, o tempo diário adicional do aluno pode e deve ser usufruído para além da escola, articulado a outras instituições da sociedade.

Além dos argumentos anteriormente mencionados, consideramos pertinente abordar que tem sido comum, em algumas realidades do país, a utilização do projeto da escola de jornada ampliada como artifício político nos períodos de campanhas eleitorais. Nesse sentido, quase sempre se observa, nos discursos proferidos por alguns candidatos, a defesa dessa modalidade de escola como saída para melhorar a qualidade da educação pública ou para solucionar a questão da ociosidade infanto-juvenil.

Outra justificativa utilizada para a criação de projetos escolares de jornada ampliada, que ao nosso ver; por si só, não se explica, diz respeito ao cumprimento de leis criadas especificamente com essa finalidade.

Além desses argumentos aqui evidenciados, outros podem estar no bojo das propostas atuais de ampliação da jornada escolar, o que nos desafia a acompanhar, em sua dimensão prática, os projetos e programas em curso no país. 


\section{Algumas considerações}

A primeira consideração que tecemos se refere à diferença existente entre ampliação da jornada escolar e educação integral. Em outras palavras, as inferências dos autores demonstraram que, a ampliação da jornada escolar do aluno se configura apenas no aumento do tempo diário do aluno na escola ou sob a responsabilidade dela. Já a educação integral corresponde ao desenvolvimento dos aspectos necessários para uma qualidade educacional, tais como: cognitivos, culturais, éticos, estéticos e políticos, dentre outros.

Não obstante, vale destacar que a discussão levantada anteriormente evidenciou um considerável aumento de experiências em âmbito nacional, que se configuraram por meio da ampliação da jornada escolar. Em nosso entendimento, esse fato está diretamente relacionado à publicação pelo governo federal de documentos legais, que estimulam financeiramente o aumento do tempo diário do aluno sob a responsabilidade da escola. Por outro lado, temos projetos e demais iniciativas que preconizam a ampliação da jornada utilizando-se de outros espaços da comunidade ou da cidade.

Ao estudar sobre as diferentes formas em que se realizam a ampliação do tempo escolar no Brasil, Cavaliere (2009) apresenta, para fins didáticos, dois possíveis formatos organizacionais pelos quais se configuram as propostas de ampliação do tempo escolar no país, sendo estes denominados "escola de tempo integral" e "alunos em tempo integral". O primeiro formato aposta no fortalecimento da instituição escolar e para isso sugere "mudanças em seu interior pela atribuição de novas tarefas, mais equipamentos e profissionais com formação diversificada, pretendendo propiciar a alunos e professores uma vivência institucional de outra ordem" (CAVALIERE, 2009, p. 53). Já o formato esquemático "alunos em tempo integral" enfatiza a oferta de atividades escolares diversificadas aos educandos no turno oposto ao período das aulas do ensino regular, ou seja, no contraturno, a partir da "articulação com instituições multissetoriais, utilizando espaços e agentes que não são os da própria escola, pretendendo propiciar experiências múltiplas 
e não padronizadas" (CAVALIERE, 2009, p. 53).

Tendo em vista esse pressuposto, podemos inferir que as questões que envolvem a ampliação da jornada escolar, atualmente, se configuram em múltiplas concepções, ideias e práticas emergentes na educação brasileira, que precisam ser exploradas, sobretudo de modo aprofundado em trabalhos acadêmicos.

Por fim, concluímos que a ampliação da jornada escolar demanda maiores investimentos e uma reorganização do equipamento escolar. Nesse sentido, acreditamos que, mesmo com um planejamento, desafios estruturais e operacionais poderão emergir quando da materialização da proposta, cabendo à comunidade escolar buscar soluções práticas para sua resolução, por um lado, e, por outro, mais vontade política de nossos governantes.

\section{Referências}

ALGEBAILE, Eveline. Escola Pública e Pobreza no Brasil: a ampliação para menos. Rio de Janeiro: Lamparina, FAPERJ, 2009.

ARCOVERDE, Yvelise Freitas de Souza. A arquitetura do tempo na cultura escolar: um estudo sobre os Centros de Educação Integral de Curitiba. 2003. 406 f. Tese (Doutorado em Educação) - Pontifícia Universidade Católica de São Paulo (PUC-SP), 2003.

ARROYO, Miguel Gonzales. O direito ao tempo de escola. Cadernos de Pesquisa, São Paulo, n. 65, p.3-10, 1986.

BRASIL. Lei No 9.394 de 20 de dezembro de 1996. Estabelece as diretrizes e bases da educação nacional. Diário Oficial da União, Brasília/DF, 23 de dez. 1996.

. Decreto № 6.253 de 13 de novembro de 2007. Dispõe sobre o Fundo de Manutenção e Desenvolvimento da Educação Básica e de Valorização dos Profissionais da Educação - FUNDEB, regulamenta a Lei no 11.494, de 20 de junho de 2007, e dá outras providências. Diário Oficial da União, Brasília/DF, 14 de nov. 2007. 
CAVALIERE, Ana Maria Villela. Quantidade e Racionalidade do Tempo de escola: debates no Brasil e no Mundo. Rio de Janeiro: Teias, v. 3, n. 6, jul./ dez. 2002.

. Tempo de escola e qualidade na educação pública. Educação

e Sociedade, Campinas, v. 28, n.100, p.1015-1035, out. 2007.

Escolas de tempo integral versus alunos em tempo integral.

Em aberto, Brasília, v.22, n.80, p.51-63, abr. 2009.

MAURíCIO, Lúcia Velloso. Políticas Públicas, tempo, escola. In: COELHO, Lígia Martha (Org.). Educação integral em tempo integral: estudos e experiências em processo. Rio de Janeiro: FAPERJ, 2009.

MENEZES, Janaína S.S. Educação integral \& tempo integral na educação básica: Da LDB ao PDE. In: COELHO, Lígia Martha (Org.). Educação integral em tempo integral: estudos e experiências em processo. Petrópolis, RJ: DP et Alli; Rio de Janeiro: FAPERJ, 2009

MONLEVADE, João. Estudo no. 1.159, de 2009, referente à STC n 2009 0 , do senador Inácio Arruda, que pede estudo sobre a educação em tempo integral, compreendendo jornada integral para os professores e estudantes, e, para estes, introdução de atividades de esporte, cultura e iniciação ao trabalho no currículo escolar. [S.I.], 2009.

NERY, Marcelo Cortez. Tempo de Permanência na Escola. Rio de Janeiro: FGV/ IBRE, CPS, 2009.

PARENTE, Cláudia da Mota Darós. A construção dos tempos escolares: possibilidades e alternativas plurais. Tese de doutorado. Campinas: UNICAMP, 2006.

A construção dos tempos escolares. Educação em Revista, Belo Horizonte, v. 26, n. 2, p. 135-156, ago. 2010.

RIBEIRO, Darcy. O livro dos CIEPS. Rio de Janeiro: Bloch, 1986.

ROSA, Alessandra Victor do Nascimento. Pesquisando a relação educação integral e $(\mathrm{m})$ tempo integral e currículo no Brasil - período 2000-2012: o que revelam as pesquisas de mestrado e doutorado? Tese de doutorado. Rio de Janeiro: Pontifícia Universidade Católica (PUC), 2016.

TEIXEIRA, Anísio Spínola. Educação não é privilégio. 4. ed. São Paulo: Ed. Nacional, 1977. 